\title{
Sustainable construction: construction and demolition waste reconsidered
}

\author{
Mercedes del Río Merino, Pilar Izquierdo Gracia \\ Department of Architecture Constructions. Polytechnic University of Madrid (U.P.M), Madrid, Spain.
}

Isabel Salto Weis Azevedo

Department of Applied Linguistics. Polytechnic University of Madrid (U.P.M), Madrid, Spain.

Construction activity in Europe has increased substantially in the past decade. Likewise, there has also been a commensurate rise in the generation of construction and demolition waste (C\&DW). This, together with the fact that in many European countries the rate of recycling and reuse of $\mathrm{C} \& \mathrm{DW}$ is still quite low has engendered a serious environmental problem and a motivation to develop strategies and management plans to solve it. Due to its composition, there is a significant potential to reuse and/or recycle C\&DW, and thereby, contribute to improving the sustainability of construction and development, but practical procedures are not yet widely known or practiced in the construction industry. This article (a) summarizes the different applications that are presently practiced to optimize the recovery and/or application of C\&DW for reuse, and (b) proposes various measures and strategies to improve the processing of this waste. The authors suggest that to enhance environmental effectiveness, a conscious and comprehensive C\&DW management plan should be implemented in each jurisdiction. More precisely, this study presents a holistic approach towards C\&DW management, through which environmental benefits can be achieved through the application of new construction methods that can contribute to sustainable growth.

\section{Introduction}

The built environment in general and the construction industry in particular are major consumers of natural resources and energy. Moreover, the construction sector is reported to be generating unacceptable levels of waste material (Ekanayake \& Ofori 2000). In recent years, the construction sector has become increasingly aware of the importance of the environmental impacts associated with waste generated during both the construction of new buildings and the demolition of old structures. The resulting increase in volume of construction and demolition waste (C\&DW) has burdened local waste management systems and, in some cases, contributed to environmental damage both locally and globally. This has caused some countries, like Spain to develop new national plans of C\&DW (PNIR 2007-2015) and to encourage local and municipal bodies to apply and enforce further regulations for $\mathrm{C} \& \mathrm{DW}$ management.

It is important to define what is meant by the 'umbrella' term C\&DW. Indeed it can cover a wide range of materials which can be categorized as follows (Symonds \& Associates 1999).

1. Waste arising from the total or partial demolition of buildings and/or civil infrastructure.

2. Waste arising from the construction of buildings and/or civil infrastructure.

3. Soil, rocks and vegetation arising from clearing and grubbing, earth moving, civil works and/or excavations for foundations.

4. Road planings and associated materials arising from road maintenance activities.

The construction sector generates a huge amount of waste in the different phases of the construction process, from the extraction of the raw materials, during the manufacture of materials, the construction process itself, its demolition and finally the disposal of the waste materials in landfills. 
On the one hand, considering sustainable construction, as defined by the Brundtland Commission (1987): 'development that meets the needs of the present without compromising the ability of future generations to meet their own needs', the built environment constitutes one of the main supports of economic developments, and on the other hand, its construction has significant impacts on resources (land, materials, energy, water, human/social capital) and on the living and working environment. Indeed, already in 1994, at the First International Conference on Sustainable Construction (in Florida), the responsibility of our human and natural environment was confirmed to rely on the hands of architectural and construction agents: 'the creation and responsible maintenance of a healthy built environment based on resource efficient and ecological principles'. This clear statement certified the implied links between the construction sectors and the principles of sustainable development.

In light of this situation, and keeping in mind the desirability of sustainable development it appears best for the construction industry to improve the durability and use of recycled materials in the production of new materials, as well as to diminish the production of construction waste throughout the entire construction process. Therefore, changes in rules, regulations and normatives governing this waste need to be implemented in order to encourage best practices by government agencies and private companies active in the construction sector, and to increase the rate of diversion of C\&DW from landfills (through reuse or recycling). Indeed, best management practices might be considered as competitive advantages by those firms that tend to be more environmentally and /or socially conscious.

Early successes in recovering more of this waste show the very significant potential of improving the management of this stream. The mass recovery of such waste helps to protect the environment by significantly reducing the quantity of landfilled waste and by making more rational use of the resources present in construction and demolition waste.

\section{Background overview of C\&DW recycling in Europe: the Spanish case}

The construction sector has lately been a significant production engine for economic growth in many European nations. Therefore, it is nowadays considered as a strategic sector not only because of the number of workers it employs, and of the economic turnover it develops, but also because this industry directly facilitates the growth of other sectors, including transportation and services.

Growth of the construction industry in the European Union (EU) has precipitated a noticeable increase in the generation of construction and demolition waste, which, in turn, has created a motivation to identify more efficient ways to manage this waste. Indeed, this problem has a clear environmental and legal component which involves all the construction industry participants.

The EU considers C\&DW to be a priority because it constitutes one of the largest waste streams within the EU
Table 1: C\&DW generated in European states ( $\mathrm{kg}$ inhabitant ${ }^{-1}$ year $^{-1}$ ) (Source: Symonds \& Associates 1999).

\begin{tabular}{llll}
\hline Germany & 720 & France & 427 \\
Denmark & 6000 & Italy & 350 \\
Spain & 450 & Portugal & $\mathrm{n} / \mathrm{d}$ \\
Netherlands & 730 & Greece & 200 \\
Great Britain & 530 & Sweden & 235 \\
Ireland & 285 & Finland & 200 \\
Belgium & 700 & Luxemburg & $\mathrm{n} / \mathrm{d}$ \\
Austria & 650 & EU (average) & 481 \\
\hline
\end{tabular}

$\mathrm{n} / \mathrm{d}$, no data available.

(it accounts for 450 million tonnes of waste every year, which represents about one-quarter of all waste materials generated in Europe) (Symmonds \& Associates 1999). Table 1 shows the volume of C\&DW generated in some of the European member states.

The C\&DW stream constitutes the third largest waste stream in quantitative terms within the $\mathrm{EU}$, after mining and farm waste. If one excludes earth and excavated road material the amount of construction and demolition waste generated is estimated to be roughly 180 million tonnes per year, according to the figures given by the EU Environment General Directorate (EC DG ENV 2007). According to more recent data supplied by EU Comission, in EU-27, on average, approximately $55 \%$ of the produced C\&DW is reused or recycled.

Three main incentives are in placed today in Europe to mitigate the potential for $\mathrm{C} \& \mathrm{DW}$ to contaminate the environment.

- Increased enforcement by regulatory agencies of existing rules for the proper management of C\&DW.

- Encouragement of industry to identify and apply appropriate recycling measures for their waste streams.

- Increased tipping fees for C\&DW disposed of on land.

The management policies for C\&DW differ considerably from one member state to another, as do the levels of environmental protection required for disposal. Although some member states introduced waste managing procedures based on prevention, recovery and restrictions and even a ban on disposal to landfill nearly 10 years ago, the waste generated by most of the member states is quite simply in broad terms disposed of to landfill without being sorted or any particular precaution being taken with regard to the hazards posed by certain constituents, as can be read in the report of the EU on Management of $C \& D W$ from year 2000 (EC DG ENV 2000).

Table 2 shows the estimated construction and demolition recycling rates (apart from clearing and grubbing, earth moving waste) of the 15 member states, illustrating the wide variety in the management of that waste within the EU. Since much of the C\&DW stream is inorganic materials (such as concrete, asphalt and steel), most of this non-recycled waste 
Table 2: C\&DW generation and recycling (summary table) (Source Symonds \& Associates 1999).

\begin{tabular}{lccc}
\hline $\begin{array}{l}\text { Member } \\
\text { state }\end{array}$ & $\begin{array}{c}\text { 'Core' C\&DW } \\
\text { generation } \\
\text { (million tonnes, } \\
\text { rounded) }\end{array}$ & $\begin{array}{c}\text { \% Re-used } \\
\text { or uecycled }\end{array}$ & $\begin{array}{c}\text { \% Incinerated } \\
\text { or landfilled }\end{array}$ \\
\hline Germany & 59 & 17 & 83 \\
UK & 30 & 45 & 55 \\
France & 24 & 15 & 85 \\
Italy & 20 & 9 & 91 \\
Spain & 13 & $<5$ & $>95$ \\
Netherlands & 11 & 90 & 10 \\
Belgium & 7 & 87 & 13 \\
Austria & 5 & 41 & 59 \\
Portugal & 3 & $<5$ & $>95$ \\
Denmark & 3 & 81 & 19 \\
Greece & 2 & $<5$ & $>95$ \\
Sweden & 2 & 21 & 79 \\
Finland & 1 & 45 & 55 \\
Ireland & 1 & $<5$ & $>95$ \\
Luxemburg & 0 & $\mathrm{n} / \mathrm{a}$ & $\mathrm{n} / \mathrm{a}$ \\
EU-15 & 180 & 28 & 72 \\
\hline & & &
\end{tabular}

is disposed of in landfills although in many cases it benefits from volume reduction via combustion in incinerators.

As can be seen, approximately $28 \%$ of construction waste in the EU was recycled 9 years ago, and countries such as The Netherlands (recycling almost all the construction waste, 95\%, Belgium (recycling 87\%) and United Kingdom (45\%) stand out as the nations where recycling rates are higher. However, in certain countries such as Spain, Italy, Portugal and Greece the market for recycled materials has not yet evolved and there are few of the necessary infrastructures for recycling. The entrained natural resources are likely of a sufficient quality and quantity to meet the demand for building materials at a moderate cost. Moreover, the market for recycled materials is not highly developed in those countries.

The rules and regulations governing the management of this waste stream in the member states also reveal the diversity of approaches to its management. The regulations are rarely binding in most member states. Only some member states have specific management legislation. However, those countries (and in particular The Netherlands, Denmark and Belgium) which have introduced measures to improve its management have achieved high levels of recycling, thus demonstrating that construction and demolition waste has a very high recycling potential.

Examples in the EU where C\&DW management policies have been practised for some time now, and which have proved to be quite successful, as is the case of The Netherlands (McDonald \& Smithers 1998) are of great interest and can serve as a model. In this country, implementation of environmental policies have focused on a specific target-group the construction industry - providing incentives for the use of renewable resources and secondary resources (materials reclaimed after construction and demolition waste. The policy also aims to reduce waste generation at the source and stimulate the reclamation of construction and demolition waste. This entails a reduction in volume of waste produced during building activities, the separation of waste material, and a twofold increase in the use of C\&D waste. In addition, this sustainable construction would aim to reduce fugitive emissions of particulates and other pollutants into the environment during the production of building materials and the construction production process.

Looking closely at the case of Spain, the first National Plan of C\&DW management enforced in 2001 (I PNR 2001) forecast a C\&DW generation of 42 millions tonnes (approximately 1 tonne inhabitant ${ }^{-1}$ year $^{-1}$ ). Even further, this plan expected to achieve the recycling of $40 \%$ of the generated C\&DW in 2006. However, data obtained recently shows that this C\&DW generation figure has been greatly surpassed, especially in some autonomous regions (II PNRCD 2007-20015). Indeed, the C\&DW generation has increased in Spain in the last 5 years at a rate of $8.7 \%$ annually (II PNRCD 2007-20015). At the same time, figures show that $90 \%$ of this waste ends up in landfills, because the low dumping fees. This situation has raised the need to issue a second National Plan of C\&DW (II PNRCD 2007-20015) which has recently come into force (February 2008) regulating the production and management of C\&DW. This new normative implies the direct application of the principle of responsibility both towards the producer and the holder of this waste and encompasses all aspects of construction activities. In addition, this strategy needs to be combined with other environmentally sound practices in order to move towards ecologically sustainable development through the development of 'best management practices'.

\section{Composition and C\&D waste characterization}

Construction and demolition waste is mainly produced during the demolition, rehabilitation, refurbishment or enlargement of buildings, and other infrastructures.

Regarding its composition, the European Catalogue of Waste (Directive 75/442/CEE and 94/904/CE) classifies the C\&DW in eight groups:

- mixture of concrete, bricks, tiles and ceramics,

- wood, glass and plastic,

- bituminous mixtures, tarmacadam and other tar products,

- metals (including their alloys),

- soil (including that which is excavated from contaminated areas), stones and dredged soil,

- insulation materials and construction materials containing asbestos,

- gypsum based materials,

- mixed construction and demolition materials. C\&DW typically includes at least small quantities of organic wastes, such as food waste and wrappers discarded into conveniently located C\&DW bins by workers at the construction and/or demolition site. 
Of all the C\&DW generated, the greatest percentage quantity corresponds specifically to that of masonry waste (masonry debris) and concrete waste (Symmonds \& Associates 1999). For example, the I Spanish National Plan for C\&DW (I PNR 2001) cites the percentage in weight of materials forming C\&DW as follows:

- bricks, tile or ceramic materials (masonry): $54 \%$

- concrete: $12 \%$

- stone: $5 \%$

- sand, gravel and other aggregate: $4 \%$

- wood: $4 \%$

- glass: $1.5 \%$

- plastic: $1.5 \%$

- metals: $2.5 \%$

- asphalt: $5 \%$

- gypsum: $0.2 \%$

- paper: $0.2 \%$

- rubbish: 7\%

- others: $3.1 \%$.

The vast majority of C\&DW is considered to be 'inert', that is, non-dangerous, since they do not experience any significant physical, chemical or biological transformation when exposed to the weather in a landfill (Figure 1). Indeed, legislation concerning this type of waste (I PNR 2001) considers it to be inert, although it is not strictly so. In general, the inert waste is neither soluble nor combustible, and does not react physically nor chemically or in any other way. The construction waste is not biodegradable, and does not affect any material in contact with it, nor does it produce any contamination that can harm the environment or human health. However, although C\&DW is described as inert, this is not truly so, since much of the C\&DW stream is comprised of materials that can and do decompose or otherwise leach chemicals into the environment. As a consequence, special attention needs to be paid to C\&DW materials which are hazardous products, in accordance with the EEC Directive 91/689/CEE on dangerous materials, although being classified as inert. These include among others, concrete additives, adhesives, glues and sealants, asbes- tos-based materials, wood treated with pesticides, or other types of toxic products, certain paints, solvents, and also the presence of gypsum board in landfills contributes to the formation of hydrogen sulfide as a fraction of landfill gas, ...etc.

Another characteristic of this type of waste, hence, is that of the leachability of the debris, the contaminating content of the waste and the ecotoxicity of the leachate although sometimes insignificant, can imply some risk for the superficial or underground waters. The literature includes many citations of (a) groundwater contamination caused by leaching from C\&DW sites; and (b) landfills gas generated from even small quantities of organic waste materials that are commonly (if illegal) co-disposed with supposedly inert C\&DW.

\section{Masonry waste}

Masonry waste originates from two different sources. Firstly, approximately $60 \%$ of masonry waste comes from demolition works. In this type of waste, great varieties of materials are included, such as brick, calcium-siliceous brick mixed with concrete and possibly also cement mortars.

The properties of this type of waste vary greatly depending on the origin of the waste. In the case of demolition waste, the properties not only depend on the type of structure from which they are generated, but also stand on its the main components, whether it be brick, calcium-siliceous bricks or concrete (Figure 2).

\section{Concrete waste}

Concrete debris refers to the waste coming from crushed concrete: concrete manufactured with Portland clinker cement and natural aggregates, rolled or crushed, coming from crystallized dreg or a combination of the two. This waste is mainly produced from the demolition works of structures, roads, or other civil works and has a variable size depending on the type of demolition technique used. It normally includes impurities such as: metals, glass, bitumen, organic material and sulphates, etc. As noted earlier, the European Community survey (II PNR 2008) showed that concrete represents about $75 \%$ of the total volume of demolition waste, underscoring the importance of seeking practical solutions for its reuse.
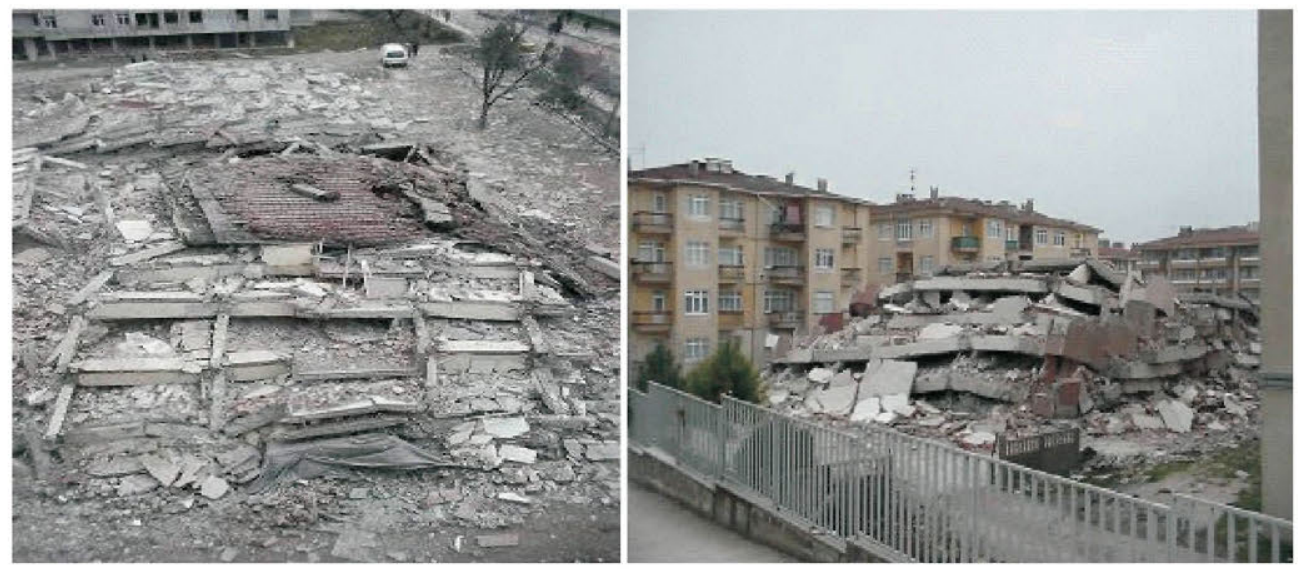

Fig. 1: Demolition works. Majadahonda, Madrid autonomous community (June 2007). 


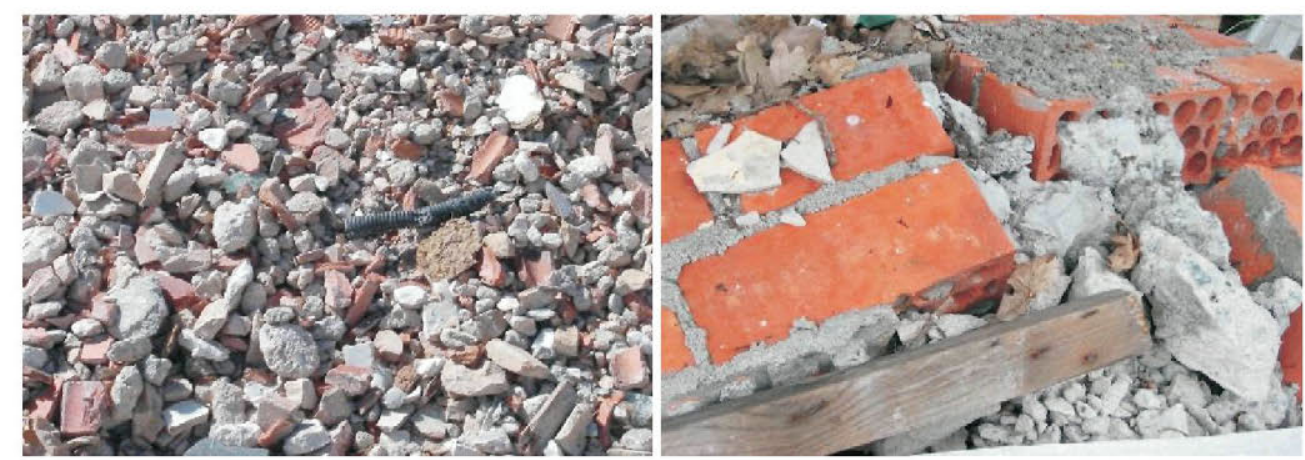

Fig. 2: Masonry waste at recycling plant, Navalcarnero, Madrid Aautonomous community (June 2007).

\section{C\&DW recovery}

Two distinct procedures can be used to minimize the production of this waste: (a) apply source reduction techniques both on site and during the design and procurement phases of a building project, and improve the management of that waste generated on site; and (b) implement waste management strategies in which all the participants in the construction process should be involved, allocating responsibilities between the construction manager, the main contractors and trade subcontractors.

One important application derived from recycling C\&DW is the production of aggregates to be used in other constructions. Up to very recently only $6 \%$ of the aggregate production was produced from recycled waste (Arab 2006). This would suggest that there is a significant opportunity to expand the use of recovered aggregates to reduce both the use of virgin sources and the volume of $\mathrm{C} \& \mathrm{DW}$ requiring land disposal.

One of the main problems with the use of recycled aggregate originated from C\&DW is that manufacturers have shown little interest in reusing it as an alternative raw material, and disregard the possibilities and applications of this material at the end of its useful life. It is only recently, with the coming in force of the new Decree on C\&DW Management Plan (II PNR February 2008), that Spain has contemplated economic incentives to 'green' companies which have already implemented environmental practices.

Prices for secondary materials (post-consumer waste) from any source vary based on many factors, including the 'purity' of the waste. It should be noted that production of high quality homogeneous materials from C\&DW is often costly and the processing costs may not be recoverable through the sale of processed materials at prevailing market prices (Figure 3).

\section{Waste processing}

In general, a typical approach used in the industry for producing aggregate from masonry waste as a substitute for virgin aggregate in new construction, as for example in Spain, is to start with a classification of the waste in two different sizes, with a difference of $40-50 \mathrm{~mm}$ in accordance with the regulations for recycled aggregates established by the Madrid municipal normatives (Figure 4). Pieces that are smaller than this size are rejected because they normally contain a great quantity of impurities (gypsum, wood, steel, coal and glass). Once this classification has taken place, the next step is to crush the waste using a hammer crusher or impact crusher, followed by a second grinding. After this, the elimination of impurities takes place using either the dry method or the thermal method in a later stage. In the latter one, the system suffers significant thermal transformations (temperature changes and/or heat transfer). Two common thermal methods applied to waste are pyrolysis and gasification. In Spain nevertheless, the most widely used method is the dry method consisting in manually separating the large size impurities in a first phase to later crushing them to separate out the smaller size units.
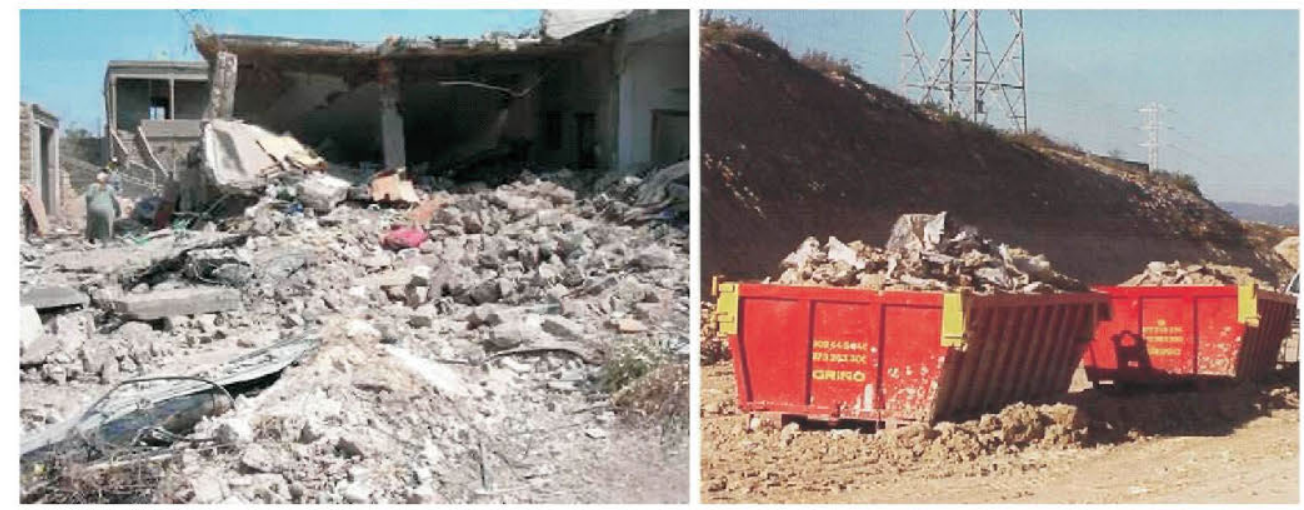

Fig. 3: Demolition works waste. La Rozas, Madrid autonomous community. (June 2007). 


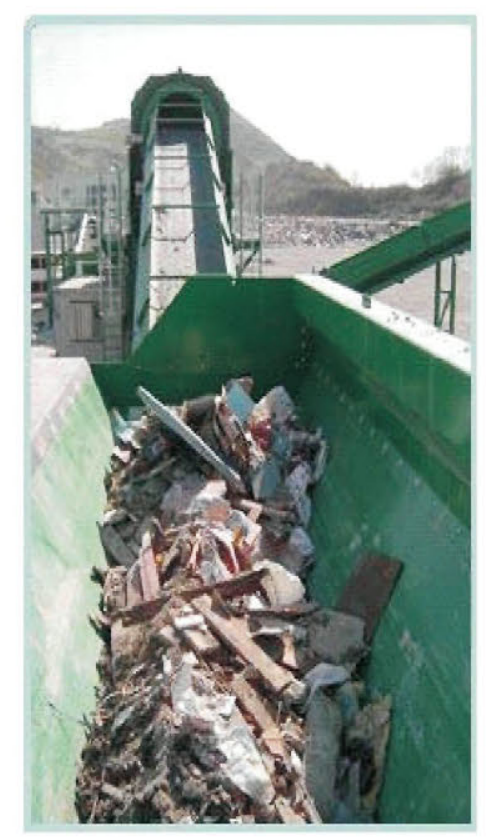

Fig, 4: C\&DW recycling plant.

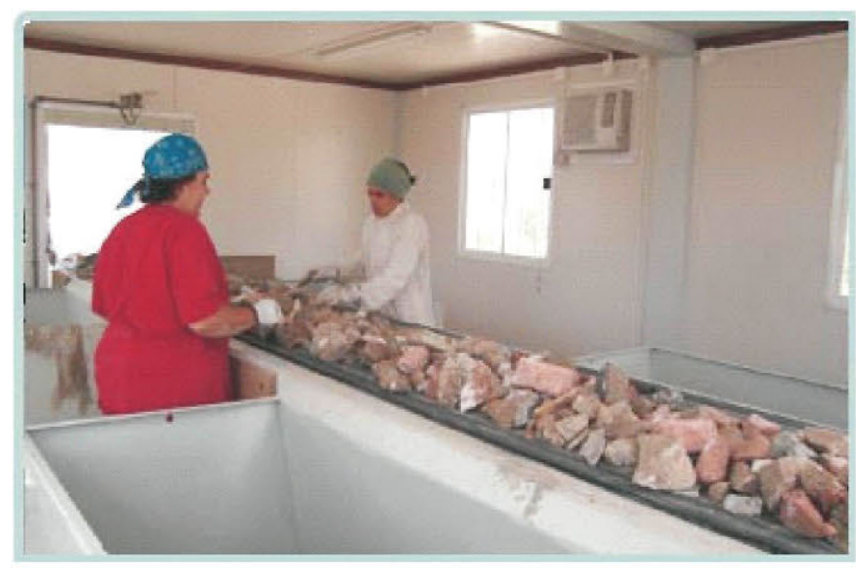

Fig. 5: Manual selection at the recycling plant.

To generate recycled aggregates from concrete waste the procedure generalized is to first crush concrete debris to a maximum size of $1200 \mathrm{~mm}$, when the grinding is done in fixed plants, and of 400 to $700 \mathrm{~mm}$ when using a movable plant (Barra de Oliveira \& Vasquez 1996). Later, the waste is taken to a central plant where it is subject to a second grinding by impact, using a hammer crusher and a conical crusher machine. When this step has been completed, the contaminating elements of the waste are eliminated (basically the steel remains), and finally, the aggregate is stored according to sizes (coarse aggregate $(65-80 \%)$ and fine aggregate) and separated from the natural one.

In order to produce a recycled aggregate that meets the industry specifications, namely a reliable consistency with minimal impurities, a pre-selection of materials before the demolition is needed (Figure 5). When the waste comes from new construction works, it makes the process easier, since it includes the possibility of carrying out a selection at the production site and the separation into the different categories is a straightforward task. On the contrary, the classification of aggregates from demolition origin is a much more complex process. Before and during the demolition process, the contractor must separate the materials to prevent mixing and contamination of the recyclable materials. Demolition needs to be selective and this represents an increase in time for the processing as well as an increase in the processing costs. Nevertheless, the economic saving derived from selecting the debris during the demolition processing is far greater as this process implies a higher quality in the recycled aggregate and there is no need to perform a further selection at the recycling plant. Indeed, this has made governments and institutions - in Spain in the II C\&DW management Plan (II PNR 2008) - seek to reward companies producing a cleaner and more homogeneous product from C\&DW with higher prices paid for this product as opposed to the poorly separated or contaminated material that would result without the extra processing. Another economic saving derives from the fact that with this process, the transportation costs to the dump or landfill sites and the disposal fees are eliminated or greatly reduced.

\section{Properties of recycled aggregate}

The construction industry establishes a difference between the diverted product originating from masonry waste and concrete waste.

\section{Properties of masonry waste derivate}

Masonry debris varies greatly in size, depending on the demolition techniques applied. The pieces can reach up to $700 \mathrm{~mm}$ when the waste comes from rejected bricks. In this case the properties of the waste are quite homogeneous and mainly depend on the type of brick being manufactured. For the same reason, the chemical composition of masonry waste is very heterogeneous, and it greatly relies on the properties of the main component.

Aggregate from masonry waste is generally considered to have at least $65 \%$ of crushed masonry as the main component (Luxan \& Borrego 2007). For the secondary components the following upper weight limits are typical: light concrete $(20 \%)$, aerated concrete $(10 \%)$, ceramic materials $(20 \%)$, natural stone (20\%) and mortar (25\%). The properties of the new aggregate will basically depend on the waste composition.

Although the density depends on the type of brick used, broadly speaking, it can be said that reclaimed masonry suitable for reuse as aggregate has a density from 1000 to $1500 \mathrm{~kg} \mathrm{~m}^{3}$. A disadvantage derived from this waste aggregate is that it has a greater porosity and therefore a greater moisture absorption coefficient as compared to aggregates made from virgin materials.

In general, the substitution of natural aggregate for this type of aggregate is not recommended in aggressive environments the ones having acidity values below $\mathrm{pH} 7$ - such as the coastal or marine ones. 


\section{Applications and secondary materials of masonry waste}

Nowadays aggregates derived from masonry waste are used for the following purposes.

- Aggregates for non-fines light concrete.

- Aggregates for mortars.

- Aggregates in new concrete used for foundations: concrete structures both reinforced and mass concrete. These types of concrete show lower strengths than the ones made with natural aggregates except for the case when $20 \%$ more cement is added.

- Aggregates for the manufacture of roof elements.

- Aggregates for the manufacture of concrete blocks.

- Aggregates for the manufacture of concrete tiles, etc.

\section{Properties of concrete waste derivates}

An application derived from recycling this debris is the production of suitable aggregates which, having been conveniently treated in the recycling facility, can be of great advantage by decreasing the use of virgin raw aggregate and by reducing the volume of this waste requiring disposal at landfills (Figure 6).

Logically, the properties of recycled aggregate depend on the composition of the concrete waste from which it originated ( $75 \%$ of concrete waste) and at the same time, on the other components of cement hydration, such as silicates and hydrated calcium aluminates or calcium hydroxide. In addition, these aggregates have components from cement hydration attached (approximately $30 \%$ in aggregates of $16-32 \mathrm{~mm}$ and $60 \%$ for the $4-8 \mathrm{~mm}$ sizes).

Recycled aggregates are more irregular and have a more porous and rough texture, although the shape coefficient is similar to the crushing of a limestone rock. Its density is slightly lower than that of natural aggregate (approximately 5-10\%).

Recycled coarse aggregates tend to absorb substantially more water than virgin aggregates, therefore, recycled aggregates should normally be used under saturation conditions, namely maintaining an optimal hydration. Thus, it is common to equip storage areas for C\&DW-derived aggregates with water sprinklers to maintain optimal hydration and suppress the emissions of escaping dust.
The recycled product obtained is a mixture of coarse aggregate $(65-80 \%)$ and fine aggregate. Recycled coarse aggregate shows a granular structure that would be suitable for all applications, whereas the use of recycled fine aggregate will likely lead to an increase in water consumption, but at the same time it shows a decrease in mechanical strength and in workability. Therefore, it is not appropriate to use sizes smaller than $4 \mathrm{~mm}$ to produce new concrete.

Another benefit of the production of diverted waste is that the use of $20 \%$ of recycled aggregates by weight in the production of new concrete could preclude the extraction of almost 7.7 million tonnes per year of stone from quarries, which means an important reduction in the impact on the landscape, as well as a corresponding decrease in the production of quarrying waste.

\section{Applications and secondary materials of concrete waste}

Although in Spain, for example, use of this type of waste is becoming a common practice, new aggregates originating from C\&DW are used for non-demanding applications and are mainly used as packing for bases and sub-bases in road construction or solid waste landfills. Up to now, many researchers have studied the use of structural concrete made with recycled aggregates. Some studies focus on the properties of the resulting concretes according to the different proportions of recycled aggregates used, others centre on the characteristics of the fine or coarse aggregate being used; and even some research has specified the addition of other no-stone materials as recycled products.

Many researchers have studied the mechanical properties (Hansen 1986; RILEM 1994, Barra de Oliveira \& Vasquez 1996) and durability (Banthia \& Chan 2000, Levya \& Helene 2004, Rahal 2007, Del Río et al. 2006) of concrete made with recycled aggregates. Research findings show that the mechanical properties depend on the characteristics of the concrete from which the aggregate is produced and the percentage of it becoming part of the new concrete. As has been proved (Levya \& Helene 2004), the substitution of $30 \%$ of the aggregate does not alter the strength or other key properties of concrete, but when $100 \%$ is substituted, the compressive strength diminishes by between 10 and $20 \%$ or the water/cement ratio is decreased (Rahal 2007). Even more, this new concrete can
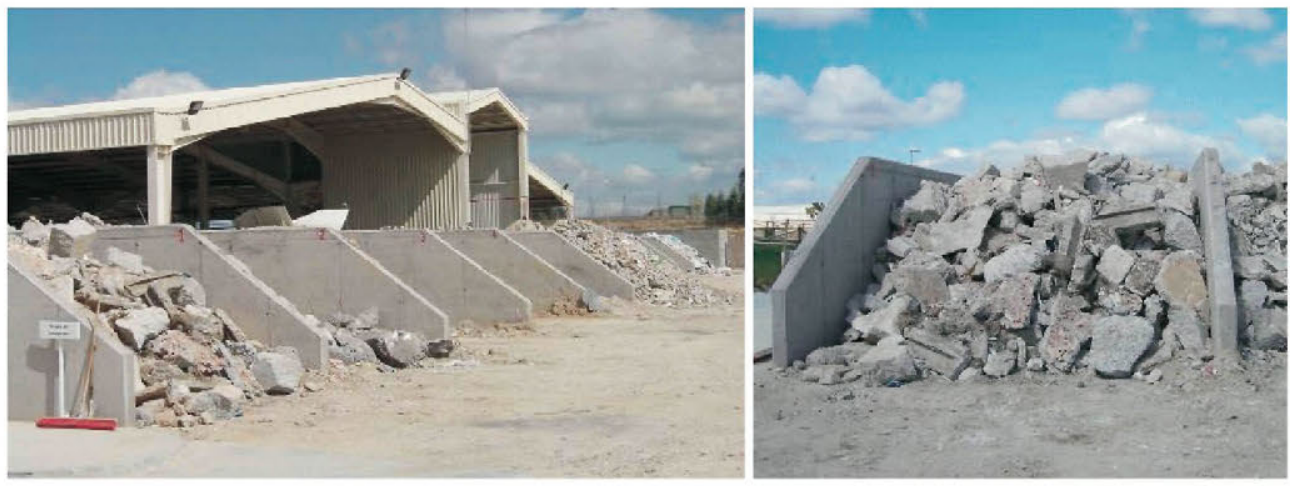

Fig. 6: Waste sorting at recycling plant, Navalcarnero, Madrid autonomous region. (June 2007). 
include up to $50 \%$ of recycled aggregate when this aggregate is dry and should be included before the mixing operation (Levya \& Helene 2004). In fact, when natural aggregates are substituted with $20 \%$ of aggregates recovered from concrete waste the resulting mix shows similar or even higher performance characteristics to the conventional one (Rao et al. 2007). Other developments have shown that the use of recycled aggregates affects the freezing and thawing behaviour of concrete, altering the elasticity module (Del Río et al. 2006).

Few studies have addressed situations in which nonstructural concrete is needed, especially in the manufacture of prefabricated elements (which are not subject to high mechanical demands), but there is a great potential to be developed: use as packing, mortar beds, pavings and for other non-structural purposes such as roof tiles, channel units, etc. Although the industry has scarcely included the use of recycled aggregates in this type of production, these applications of concrete waste should be further developed and extended. Indeed, advances in technology open up possibilities of further research studies on other uses of concrete waste. An example of this being the research works performed by the ITEC (Technological Construction Institute) and the Waste Council of the Generalitat of Catalonia (Spain), proving that materials complying with the specifications on granulometry, volumetric stability and maintenance of the bearing capacity can be used with good results for soils as packing, and for foundations in light constructions, such as family houses, garages, etc. (Del Río et al. 2006). Furthermore, the small fractions obtained from concrete recycling can be used to improve the soil granulometry, or as drainage systems and can help in the neutralization of acids.

\section{Environmental considerations}

All construction activities have impacts on the environment: on the countryside by buildings themselves, on geological resources by the extraction and use of materials, on air and water quality by emitting pollutant gases and liquids, by consuming energy and producing solid waste on building and demolition sites. The rational use of natural resources is an essential component when applying the principle of sustainable development. Therefore, energy consumption is an important consideration when processing C\&DW to create new aggregates, since it takes substantial energy to run the grinding and other size-reduction equipment. Not many studies have focused on this important issue up to now. Only recently, some projects are being developed comparing the energy consumption of waste diverted products and that from producing new aggregates from virgin materials but without any conclusions yet (Rodríguez et al. 2007).

Considering C\&DW, a basic aspect to bear in mind is the fact that economic interests together with environmental ones merge at the same point.

Regarding the production of C\&DW, the development of environmental policies in order to reduce costs of C\&DW management has proved to be beneficial. Experimental building sites have shown that effective action to prevent the generation of waste is a great advantage towards achieving sustainable development (choice of building materials, architectural techniques, etc.) (Craven et al. 1994, Minks 1994, Ruch \& Rentz 1994). In addition, incorporating environmental factors into construction and civil-engineering practice such as incentives to recycle C\&DW and the development of C\&DW management plans are also a major contribution to the aim of achieving sustainable growth. These environmental policies take into consideration both quantitative (volume of C\&DW production) and qualitative measures (reduction of hazards posed by this waste).

a. In terms of quantitative measures, when a building or civil engineering structure is designed, architects, prime contractors and suppliers should consider C\&DW production in the technical choices that they make, in order to reduce the amount of waste generated by future demolition and to make it easier to re-use materials and carry out selective demolition. The design of new, and the maintenance of existing, structures should also help to extend the life of such buildings.

b. Regarding qualitative measures (reducing the hazards posed by construction and demolition waste), measures must first of all be taken to limit the use of dangerous substances in the construction of new buildings. For this purpose, the manufacturers of construction materials need to eliminate the use of dangerous substances in the manufacture of these products at the design stage. Controlling the use of dangerous substances will reduce the adverse environmental impact of managing such waste and will make it easier to manage the general C\&DW.

Another environmental advantage to underline is that C\&DW recycling enables large quantities of resources to be used rationally which otherwise would have to be extracted from the diminishing stock of non-renewable resources. Indeed, the recycling of mineral wastes enables the environmental impact of quarrying or mining (transport, noise nuisances, vibration, surface and groundwater pollution, waste, visual and aesthetic impacts, changes to the topography and natural habitats) to be reduced. Indeed C\&DW recovery extends the useful life of dumps, implying with it a saving in the consumption or import of resources and raw materials they substitute. In this way, the reuse of C\&DW reinforces the preservation of natural spaces as well as reduceing the exploitation of mineral resources or quarries. Recycling of C\&DW enables the environmental impact of construction to be reduced as compared with the extraction of primary aggregates and the disposal to landfill of an equivalent quantity of C\&DW.

Finally, the disposal to landfill of C\&DW also has impacts on the environment: leaching of the decomposition products of certain non-inert components (plaster, plastic, wood, bitumen, hazardous waste such as paints, etc.) transport over greater distances than involved in on-site recycling. 
Recently, Spanish researchers have analysed and evaluated the application of the environmental management system (EMS) ISO Standards 14001 to construction sites in the Autonomous Community of Madrid, paying particular attention to control and management practices for waste generated on site, and to the fulfilment of legislation on waste management (Rodríguez et al. 2007). The authors compared construction waste management on sites, with and without EMS, in order to detect possible deficiencies of EMS and current management instruments. The research is based on the collection, statistical treatment, analysis and interpretation of data obtained from a survey completed by personnel in charge of various construction works in progress in Madrid. The results suggest that EMS on worksites helps promote the fulfilment of the relevant current legislation and the appropriate management of solid, inert and hazardous waste. For example, with regard to reuse, $11.8 \%$ of inert waste from EMS sites is reused on another site, as against $5.8 \%$ on non-EMS-sites.

\section{Suggested legal and regulatory measures to improve the reuse and recycling of C\&DW: the Spanish case}

Overall, our study highlights deficiencies in the application of appropriate waste management practices by construction companies in Spain. Four conditions attached to achieving a significant level of C\&DW recycling and directly influencing environment have been identified throughout the experience obtained in Spain. After the failure of the first National C\&DW Management Plan (EC DG ENV 2000) the second one issued recently (II PNRCD February 2008) includes the following statements.

1. Landfill sites must be properly managed and illegal dumping bans must be enforced and penalties assessed per the prevailing regulations.

2. Holders of demolition and construction waste must pay a significant amount for the disposal of such wastes (tipping fees), while dangerous, unsorted waste must incur a higher cost in order to avoid contamination and thus to discourage mixing.

3. (Sorting and crushing) facilities must be made available for treating the inert part of construction and demolition waste for recycling purposes.

4. This must prompt tacit acceptance by potential users of recycled aggregates as substitutes for virgin aggregates and that there must be no discrimination on the basis of an aggregate's origin.

Certain barriers that hinder the increase of C\&DW recycling and reuse rates are identified.

- Promoters usually do not include specific budgetary allocations for C\&DW management and do not facilitate waste management plans by including them in the technical specifications, or by making provision for the use of recycled material.
- National and regional governments are slow to apply C\&DW management plans which have been approved. For example, the regional Plan for Integrated Management of C\&DW established the creation of a net of public facilities to guarantee the integrated management of C\&DW (i.e. transfer stations, C\&DW recycling plants, etc.); however, the implementation of recycling activities in the region is practically non-existent.

- No initiatives have been taken to launch information and awareness programmes for agents involved in the sector.

- The technical standard regarding C\&DW management and the production of recycled arid material has not yet been fully developed.

- Construction companies do not currently fulfil their obligations as producers of hazardous waste due to the high costs of managing this type of waste and the imprecision of current legislation.

In order to encourage and strengthen the reuse and recycling of C\&DW in these countries, and especially in the case of Spain we perceive that new legislation is needed to require the construction industry to alter the way C\&DW is handled, as has been successfully done in other European countries. A starting point would be the development of a C\&DW management plan to state the principles and proceedings applicable to this type of construction waste and its disposal, specifying the responsibilities and obligations of the different agents intervening in the production and management of C\&DW (Bourdeau 1999). At the same time, the new regulations should ensure the correct treatment for recycling the waste so as to maximize the recovery of construction resources, and hence contribute to a sustainable construction development. In short, an effective methodology for implementing the waste management plan has to be established and pursued.

These enforced measures can include some of those which have already been successfully put into practice in some European countries (as in the case of the Netherlands, Denmark or Germany) and have shown an effective strategy in order to reach greater control of $\mathrm{C} \& \mathrm{DW}$. The criteria concerning the improvement of C\&DW management can be divided into two blocks, planning steps and operational procedures, as has been done in other European state members.

\section{Planning steps}

This includes various measures prior to obtaining the construction works license. These measures should be defined by the administration and would include a compulsory management plan for the generated waste in all the construction works projects in the procurement process. Among others, this management plan should include measures such as the following for any construction work.

- To evaluate the volume and characteristics of the waste that is going to be generated, estimating the quantity, in tonnes and cubic metres of the C\&DW of the construction work to be built. 
- To assess the separation or selective collection of waste projected to be performed.

- To specify the recycling plant and management of the waste where it is going to be disposed, if not done on site.

- Drawings and plans of the facilities provided for storing C\&DW on site, or for other management operations to be done on the construction site. These facilities could later be adapted to the particular characteristics of the construction and its building systems, always in accordance with the construction management plan.

- Specifications in relation to the storage, handling or other management works of C\&DW on site which should be included in the Technical Specifications attached to the project.

- To estimate the cost assessment of the operations performed for handling and managing C\&DW which should be included in the bill of quantities.

All these data are to be included in a Report on Waste Management. This document normally includes the following information.

- Final destination of the waste. If the waste is to be reused or recycled on site, the special construction regulations adopted to achieve it should be explicitly stated.

- Zoning ordinances, or municipal regulations on the obligation to separate the inert material at the point of origin. Economic evaluation of the conditions under which this operation is possible and feasible.

- Study of the surface availability to perform the selection operations.

- Location of the closest authorized dumps (controlled deposits).

- Characteristics of the construction work to be demolished. All the construction system features, materials used and constructive elements liable to be recycled should also be clearly stated.

- If the works to be done are demolitions, refurbishments or restorations, an inventory listing of the hazardous waste which might be generated should be stated, specifying the selective separation, and avoiding the mixture of dangerous materials with other waste. Under all circumstances, the correct treatment of the hazardous materials is to be ensured.

- In addition, documentation should be provided ensuring that the C\&DW generated in the construction works have been correctly processed to either a processing/recycling plant or to a licensed disposal facility to be treated by an authorized waste management agency. All documents concerning C\&DW operations should be correctly filed for a period of five years (in the case of Spain).

\section{Operational procedures}

C\&DW should be classified in separated fractions when the total volume overpasses certain fixed quantities. If the owner cannot perform this operation due to a lack of physical space, an authorized management agency can be appointed for the job. This agency has to give proof that the regulations have been thoroughly fulfilled regarding the issues listed here.

- Demanding the payment by the construction companies of a financial deposit or other type of financial assurance when drawing up the municipal construction work licence. This deposit, to be stipulated by the local agencies, would respond to the correct C\&DW management plan and will be returned once the various certificates and documents showing the correct management and recycling operations or disposal process have been submitted.

- Demanding and enforcing the classification and selection of materials within the construction site.

Duties and obligations stated in the previous points should necessarily be backed up by the different public administrations. Therefore, the regulations should include provisions for governing bodies to commit themselves to rge following activities.

- Check the construction project in order to verify the selection of design alternatives generating less waste in the construction and exploitation phase as well as using designs that encourage correct environmental dismantling once the useful life of the construction has come to an end.

- Encourage alternatives for saving natural resources, using recycled construction materials or elements formed by recovered wastes, in the different construction works.

- Ensure that in the procedures of environmental assessment the project proponent considers alternative designs that would generate less waste in the construction and exploitation phases. In addition, the use of recycled products or elements originating from waste diversion, processing, and recovery should also be considered.

- Take into account in the procedures for choosing the offers and bids the inclusion of alternatives for the reduction of C\&DW or the incorporation of products that have been made from waste materials.

In addition to the regulations, there are also factors on the practical and administrative level which influence waste handling. Although clearly all the participants in the construction industry have to pursue good C\&DW management practices in the legislation there are other important factors which intervene in their performance. Table 3 gives an overview of how the construction industry participants are affected by different factors.

\section{Conclusions}

In spite of the increase of society's awareness of the need to protect the environment and to recycle, and of policies carried out to promote these principles, some European coun- 
Table 3: Ways in which construction industry players are affected by different factors (Source: Thormark 2002).

\begin{tabular}{|c|c|c|}
\hline Player & Driving force & Important influencing factors \\
\hline Developer & $\begin{array}{l}\text { Legislation } \\
\text { Environmental aims }\end{array}$ & $\begin{array}{l}\text { Attitudes of the management } \\
\text { Goal definition }\end{array}$ \\
\hline Contractor & $\begin{array}{l}\text { Legislation } \\
\text { Environmental aims } \\
\text { Cost reductions }\end{array}$ & $\begin{array}{l}\text { Attitudes of the management } \\
\text { Organization of the site } \\
\text { Waste planning }\end{array}$ \\
\hline $\begin{array}{l}\text { Building site } \\
\text { owner }\end{array}$ & $\begin{array}{l}\text { Legislation } \\
\text { Cost reductions }\end{array}$ & $\begin{array}{l}\text { Space for waste } \\
\text { Collecting system } \\
\text { Knowledge and motivation of } \\
\text { the employees }\end{array}$ \\
\hline $\begin{array}{l}\text { Waste } \\
\text { enterprise }\end{array}$ & Business & $\begin{array}{l}\text { Infrastructure of the market } \\
\text { Access to recycling plants } \\
\text { Costs, profitability }\end{array}$ \\
\hline Authorities & $\begin{array}{l}\text { EU legislation } \\
\text { Legislation }\end{array}$ & $\begin{array}{l}\text { Process for permits } \\
\text { Goals } \\
\text { Supervision }\end{array}$ \\
\hline
\end{tabular}

tries are still in the very early stages of the recycling process, as is the case of Spain. It is still common practice to dispose C\&DW in dumps and landfills with little or no attempts to recover such waste beforehand.

The management mechanisms to be developed have to embody environmental, economic, and legal issues. The implemented construction waste management plan suggested here represents the first step towards a holistic strategy for minimizing waste generation from the construction process. This C\&DW management plan should include preventive policies, which together with comprehensive regulations regarding waste separation, recycling or reuse, and disposal procedures would lead to the optimal treatment of the waste materials.

The development of an integral C\&DW management plan will definitely help to achieve the main objective of preventing and reducing the generation of C\&DW both at a local and global sphere. It will also encourage the reutilization and recycling of the waste generated, and in addition, it will ensure the adequate treatment of the waste to be disposed, in an attempt to maximize the recovery of resources contained in C\&D waste and contribute to an environmentally sustainable growth of the construction industry.

Rigorous application and implementation of the waste disposal laws and ordinances need to be enforced, and the use of recycled and re-used waste is to be promoted to mitigate the serious polluting effect caused by C\&DW. Participants involved in the construction sector have to be aware of the possible cost savings from measures which successfully prevent and diminish construction waste, as well as the environmental impacts and the long-term national and global implications.

In this way, not only the main goal of avoiding an increase in the generation of C\&DW could be reached, but the need for the reuse and recycling of the waste material generated is also encouraged. At the same time, the correct treatment of the materials to be disposed of is ensured so as to maximize the recovery of resources contained in the construction and demolition waste, contributing therefore to a more sustainable development in the construction industry.

The responsibility for C\&DW is to be passed both to the generator of that waste (construction developers) and to the holder (constructor) together with the intervention of public administrations and authorities to improve the legislation of C\&DW, in order to foster a waste-reduction culture and to minimize the production of waste. Efficient management of this waste can only be achieved with the participation of all those involved in the construction industry and the public administration agencies together with a strong enforcement programme and thorough tracking of the proposed measures.
Arab, H.B. (2006) Aggregates from C\&DW in Europe UEPG http:// www.uepg.eu/uploads/documents/pub-12_en-plaquette.pdf (Accessed 5 June 2008).

Banthia, N. \& Chan, C. (2000) Use of recycled aggregate in plain and fibre-reinforced concrete. Concrete International, 22, 41-45.

Barra de Oliveira, M. \& Vasquez, E. (1996) The influence of retained moisture in aggregates from recycling on the properties of new hardened concrete. Waste Management, 16, 113-117.

Bourdeau, L. (1999) Sustainable development and the future of construction: a comparison of visions from various countries. Building Research \& Information, 27, -54-366.

Brundtland Commission: World Commission on Environment and Development (WCED). (1987) Our Common Future, p. 43. Oxford University Press, Oxford.

Craven, D.J., Okraglik, H.M. \& Eilemnerg, I.M. (1994) Construction waste and a new design methodology. In: Sustainable Construction: Proceedings of the First International Conference of CIB TG, Tampa, FL, USA, 16 November 6-9, 1994, pp. 89-98. University of Florida, FL, USA.

Del Río, M., Izquierdo, P. \& Salto-Weis, I. (2006) Ethical and legal aspect of the use and recycling of masonry waste in Spain. In: Proc. of the Seventh International Masonry Conference, London. International Masonry Society Surrey, UK.
EC DG ENV 2000 (European Commission, Directorate-General, EnvironmenManagement of Construction and Demolition Waste, Working Document $\mathrm{N}^{\circ} 1$, April 2000). http://ec.europa.eu/enterprise/environment/index_home/waste_management/constr_dem_ waste_000404.pdf (Accessed: 5 June 2008).

EC DG ENV 2007 (European Commission DG ENV News Alert, issue 68, June 2007). http://ec.europa.eu/environment/integration/research/ newsalert/pdf/68na3.pdf (Accessed 5 June 2008)

Ekanayake, L. \& Ofori, G. (2000) Construction Material Source Evaluation. In: Proc.: Strategies for a Sustainable Built Environment, Pretoria, August 2000. Available at: http://www.sustainablesettlement. co.za/event/SSBE/Proceedings/ekanyake.pdf

European Waste Catalogue Directive 75/442/CEE.

European Waste Catalogue 94/904/CE.

Hansen, T.C. (1986) Recycled aggregates and recycled aggregate concrete Materials and Structures, 9th Meeting of RILEM General Council. Springer, Netherlands, Volume 19, Number 2, March 1986.

I Plan Nacional de Residuos de Construcción Demolición 2001-2006, BOE $n^{\circ} 166,14$ Julio 2001.

II Plan Nacional de Residuos de Costrucción y demolición (II PNRCD), included within the Plan Nacional Integrado de Residuos (PNIR) 2007-2015. Real decreto 105/2008 sobre la regulación de la producción y gestión de los residuos de construcción y demolición. 
Levya, S.M. \& Helene, P. (2004) Durability of recycled aggregates concrete: a safe way to sustainable development. Cement and Concrete Research, 34, 1975-1980.

Luxan, $\mathrm{M}^{\mathrm{a}}$ Pilar de \& Borrego, F. (2007) Reutilización del hormigón en España: perspectiva e investigaciones de áridos reciclados procedentes de residuos de construcción y demolición. Revista del Colegio Oficial de Aparejadores y Arquitectos Téenicos de Madrid. [Concrete Reuse in Spain: perspectives and researc on recycled aggregates fromn construction and demolition waste].

McDonald, B. \& Smithers, M. (1998) Implementing a waste management plan during the construction phase of a project: a case study. Construction Management and Economics, 16, 71-78.

Minks, W.R. (1994) The construction's Contractor's waste management plan: optimizing control and cost. In: Sustainable Construction: Proceedings of the First International Conference of CIB TG, Tampa, FL, USA, 16 November 6-9, 1994, pp. 765-774. University of Florida, FL, USA.

Rahal, K. (2007) Mechanical properties of concrete with recycled coarse aggregate. Building and Environment, 42, 407-415.

Rao, A. Jha, K.N. \& Misra, S. (2007) Use of aggregates from recycled construction and demolition waste in concrete. Resources, Conservation and Recycling, 50, 71-81.
RILEM 121-DRG, (1994) Specifications for concrete with recycled aggregates. Material Structure, 27, 557-559.

Rodríguez, G., Francisco, J. A. \& Germán, M. (2007) The contribution of environmental management systems to the management of construction and demolition waste: The case of the Autonomous Community of Madrid (Spain). Resources Conservation \& Recycling, 50, 334-349.

Ruch, M.\& Rentz, O. (1994) Demolition waste management strategies in France and Germany. In: Sustainable Construction: Proceedings of the First International Conference of CIB TG, Tampa, FL, USA, 16 November 6-9, 1994, pp. 363-372. University of Florida, FL, USA.

Symonds, in association with ARGUS, COWI and PRC Bouwcentrum (1999) Construction and demolition waste management practices, and their economic impacts. http://ec.europa.eu/environment/waste/ studies/cdw/cdw_chapter1-6.pdf (Accessed 3 June 2008); http:// reports.eea.europa.eu/technical_report_2001_69/en/tech_rep_69. pdf (Accessed 5 June 2008).

Thormark, C. (2002) Handling and recycling building and construction wastes. In: Workshop, 6-7 November 2002, Stockholm, Sweden. http://www.cowam-project.org/cms/Content/.../Sweden_CD_Waste. pdf Accessed: 7 June 2008) 